\title{
Angiogenesis in primary colorectal cancer and matched metastatic tissues: Biological and clinical implications for anti-angiogenic therapies
}

\author{
LEI YIN ${ }^{1}$, JIANNING LI ${ }^{2}$, DEJIAN MA ${ }^{3,4}$, DONGHUA LI ${ }^{5}$ and YANLAI SUN ${ }^{4}$
}

\begin{abstract}
${ }^{1}$ Department of Gastrointestinal Surgery, Huzhou Central Hospital, Affiliated Central Hospital Huzhou University, Huzhou, Zhejiang 313000; ${ }^{2}$ The Central Sterile Supply Department, Affiliated Hospital of Shandong Academy of Medical Sciences, Jinan, Shandong 250031; ${ }^{3}$ School of Medicine and Life Sciences, University of Jinan-Shandong Academy of Medical Sciences, Jinan, Shandong 250062; ${ }^{4}$ Department of Gastrointestinal Cancer Surgery, Shandong Cancer Hospital and Institute, Shandong First Medical University and Shandong Academy of Medical Sciences, Jinan, Shandong 250117;

${ }^{5}$ Department of Radiotherapy, Yuncheng People's Hospital, Yuncheng, Shandong 274700, P.R. China
\end{abstract}

Received August 31, 2019; Accepted February 11, 2020

DOI: $10.3892 / \mathrm{ol} .2020 .11450$

\begin{abstract}
Metastasis remains a notable issue in patients with newly diagnosed colorectal carcinomas (CRC). Although anti-angiogenic therapies target metastatic diseases, hypoxia-inducible factor-1 $\alpha$ (HIF-1 $\alpha$ ) and vascular endothelial growth factor (VEGF) status are routinely evaluated in primary tumors as metastatic sites are infrequently biopsied. The present study aimed to investigate the expression and significance of HIF-1 $\alpha$, VEGF and microvascular density (MVD) in primary tumors and corresponding metastatic CRC tissues. HIF-1 $\alpha$, VEGF and CD34 status were analyzed via immunohistochemistry analysis in 46 patients who underwent surgical resection of primary CRC ( 35 colon and 11 rectum) and matched metastases (lymph node and liver metastases) in Shandong Cancer Hospital. The association between selected biomarker status and clinicopathological characteristics was analyzed, and expression levels in primary tumors and corresponding metastases were compared. A total of 46 paired colorectal primary tumor and synchronous metastases samples were acquired for analysis using a standardized HIF-1 $\alpha$, VEGF and CD34 immunohistochemical procedure. The results demonstrated that the positive rates of HIF- $1 \alpha$ and VEGF in primary CRC were 70 and $73.9 \%$, respectively. HIF-1 $\alpha$ (60.9\%) and VEGF (58.7\%) expression decreased in the lymph metastatic samples compared with primary CRC. Conversely,
\end{abstract}

Correspondence to: Dr Yanlai Sun, Department of Gastrointestinal Cancer Surgery, Shandong Cancer Hospital and Institute, Shandong First Medical University and Shandong Academy of Medical Sciences, 440 Jiyan Road, Jinan, Shandong 250117, P.R. China E-mail: sunyanlai@126.com

Key words: colorectal carcinoma, metastasis, hypoxia-inducible factor 1- $\alpha$, vascular endothelial growth factor, microvascular density, immunohistochemistry the level of MVD in primary tumors was significantly higher compared with metastatic tumors. No significant differences were demonstrated between HIF-1 $\alpha$ and VEGF expression and the different clinicopathological features in primary CRC and corresponding metastases. Primary carcinomas and matched metastatic tissues demonstrated a moderate level of consistent immunoreactivity for HIF-1 $\alpha$ and VEGF. HIF-1 $\alpha$, VEGF and CD34 were expressed in both primary tumors and corresponding metastases of CRC, suggesting that they may be involved in the development of metastasis. HIF- $1 \alpha$ and VEGF expression in primary sites was consistent with that observed in metastases; however, it varied from that exhibited in MVD. The current analysis will improve the current understanding of the metastasis models and provide further evidence for evaluating the response to HIF-1 $\alpha$ and VEGF inhibitors.

\section{Introduction}

Colorectal cancer (CRC) is one of the most common neoplasms and constitutes a major cause of cancer-associated mortality worldwide (1). The incidence of CRC in 2018 was $6.1 \%$ (1). In CRC, $\sim 60 \%$ of patients have unresectable or metastatic disease at the time of diagnosis (2). The lymph nodes and liver are common sites of metastasis in metastatic (m)CRC (3).

Advancements in targeted therapies developed against angiogenesis have improved survival in $\mathrm{mCRC}$ as angiogenesis is known to play a key role in the development of several types of tumor (4). Hypoxia-inducible factor-1 $\alpha$ (HIF-1 $\alpha$ ) and vascular endothelial growth factor (VEGF) are both notable regulators of angiogenesis that are essential for tumor growth in CRC (5). HIF-1 $\alpha$ exists in the microenvironment in several tumor entities as the rapid proliferation of tumor cells outpaces the rate of angiogenesis (6). Overexpression of HIF-1 $\alpha$ is associated with tumor aggressiveness, invasiveness and resistance to radiotherapy and chemotherapy in CRC (7). VEGF is the principal pro-angiogenic growth factor, and its expression is mediated by HIF-1 $\alpha$ during hypoxia (8). VEGF markedly increases vascular permeability, promotes the formation of 
new blood vessels and the induces metastases in CRC (9). Thus, inhibiting HIF-1 $\alpha$ and VEGF expression has demonstrated promise for tumor anti-angiogenesis therapy in both animal models and patients with cancer (10).

In order for a biomarker to be clinically applied, the relevance of its status in both the primary tumor and metastatic sites needs to be understood. Currently, the understanding of cancer predominantly stems from the comparative study of normal tissues, paracancerous tissues and cancerous lesions (11). Only a few comparative studies on primary and metastatic tumors depend on the assumption that primary and metastatic sites are pathologically concordant in clinical practice (12). However, research has determined that different metastatic sites may have different molecular mechanisms of metastasis (13). To the best of our knowledge, the difference in HIF-1 $\alpha$ and VEGF expression between primary tumors and corresponding metastases has not yet been fully investigated in CRC.

The present study assessed HIF-1 $\alpha$, VEGF and CD34 status via immunohistochemistry (IHC) analysis on samples obtained from primary tumors and paired metastatic sites of CRC. The primary aim was to analyze the differential HIF-1 $\alpha$, VEGF and microvascular density (MVD) status between primary tumors and corresponding metastatic tissues at the protein level, and provide a potential predictive mechanism to inform the use of anti-angiogenic agents in the treatment of mCRC.

\section{Materials and methods}

Patient characteristics. The present study was approved by the Ethics and Scientific Committees of Shandong Cancer Hospital (Shandong, China), and written informed consent was obtained from all patients prior to the study start. A total of 46 patients ( 20 men and 26 women) who underwent surgical resection of both the primary $\mathrm{CRC}$ and the corresponding metastatic sites (lymph nodes and liver) synchronous between April 2010 and June 2017 in Shandong Cancer Hospital, and had complete clinical data, were reviewed in this retrospective analysis. The median age of patients was 62 years (age range, 40-82 years). The clinical and histopathological characteristics of the patients are presented in Tables I-III. All patients provided available tissues, including primary tumors and matched metastases. None of the cases underwent adjuvant therapy prior to surgery. Tumors were staged according to the American Joint Committee on Cancer (AJCC) pathological tumor node metastasis (TNM) classification (14).

$I H C$. The formalin-fixed paraffin-embedded tissues of primary tumors (46 specimens), matched lymph node metastases (46 specimens) and liver metastases (46 specimens) were collected to detect HIF-1 $\alpha$, VEGF and CD34 expression at the protein level. Briefly, specimens had been fixed in $10 \%$ formalin and embedded in paraffin, and were subsequently sectioned into $4-\mu \mathrm{m}$ sections. IHC staining was performed as previously described (15). Briefly, deparaffinized sections were pretreated with $0.4 \%$ pepsin for $60 \mathrm{~min}$ at $37^{\circ} \mathrm{C}$, and endogenous peroxidase activity was blocked by treatment with $0.2 \% \mathrm{H}_{2} \mathrm{O}_{2}$ for $3 \mathrm{~h}$. The antibodies against CD34 (cat. no. Kit-0004) and the MaxVisionTM IHC kit (cat. no. Kit-5030) that immunostained HIF-1 $\alpha$ and VEGF were all purchased from Fuzhou Maixin Biotech Co., Ltd. Tissue sections were incubated with primary antibodies against HIF-1 $\alpha$ (1:50) and VEGF (1:100) at $4^{\circ} \mathrm{C}$ for $12 \mathrm{~h}$, and CD34 was ready to use. The streptavidin-peroxidase-biotin method was performed according to the manufacturer's protocol (16). Following the primary incubation, membranes were incubated with horseradish peroxidase-labeled secondary antibody (Supervision $^{\mathrm{TM}}$ Universal Detection Reagent; cat. no. D-3004; Shanghai Changdao Biotech Co., Ltd.) The slides were subsequently stained with 3,3'-diaminobenzidine for $5 \mathrm{~min}$ at room temperature prior to counterstaining with haematoxylin. PBS was used as a negative control. Sections were examined by using the image analyzer of a light microscope (Olympus BX43; Olympus Corporation).

IHC assessment. Prior to pairing, both the primary tumors and metastases tissues in each patient were assessed by two independent pathologists at the pathology department of Shandong Cancer Hospital in a blinded manner. Staining was evaluated as reported by Qiu and Zhou (10), with a semi-quantitative analysis incorporating both the proportion of positively stained cells and the staining intensity. The immunoreactions for HIF-1 $\alpha$ were divided into four groups as follows: $0,<1 \%$ of tumor cells exhibiting nuclear immunostaining; 1, 1-10\% of tumor cells; $2,11-50 \%$ of tumor cells and $3,>50 \%$ of tumor cells exhibiting nuclear immunostaining. For VEGF, the evaluation was as follows: $0,<10 \%$ of tumor cells exhibiting cytoplasmic immunostaining; $1,11-25 \%$ of tumor cells; $2,26-50 \%$ of tumor cells and 3,>50\% of tumor cells exhibiting cytoplasmic immunostaining. The intensity of HIF- $1 \alpha$ and VEGF staining was also determined semi-quantitatively on a scale of 0-3 as follows: 0 , negative; 1 , weakly positive; 2 , moderately positive; and 3, strongly positive. The final staining score was determined by combining the percentage scores and staining intensities, as follows: 0 (negative), $+(1-4),++(5-8)$ and +++ (9). Final staining scores of 0 or + were classified as negative expression, while final staining scores of ++ and +++ were classified as positive expression. Microvessel density was visualized using immunohistochemical detection of CD34 antigen and subsequently quantified using Image Capture software (Panasonic Corporation; version 3.7) (17,18). Briefly, tumor sections were observed under a low power light microscope (magnification, $\mathrm{x} 40$ ) in three areas with the greatest degree of vascularization (hot spots of vascularization). These three hot spots were then examined at high magnification (x200) and the mean MVD for each specimen was calculated. Stained endothelial cells or endothelial cell clusters clearly separated from adjacent microvessels by tumor cells and/or stroma elements were considered a single countable microvessel. Microvessels were counted in three hot spots, and MVD was divided into low and high groups, according to a median MVD value from all samples from the present study.

Statistical analysis. Statistical analyses were performed using SPSS software (version 17.0; SPSS, Inc.). Data were expressed as the means \pm standard deviation. The associations between HIF- $1 \alpha$ and VEGF expression, and the clinicopathological characteristics of patients with CRC were assessed using the $\chi^{2}$ test. Pearson's correlation test and McNemar test were used to compare HIF- $1 \alpha$ and VEGF staining between primary tumors and associated metastatic sites (perfect correlation, 1.0). 
Table I. Association between HIF-1 $\alpha$ and VEGF expression in primary tumors and the clinicopathological characteristics of patients with colorectal carcinomas $(n=46)$.

\begin{tabular}{|c|c|c|c|c|c|c|c|c|}
\hline \multirow[b]{2}{*}{ Characteristic } & \multicolumn{2}{|c|}{$\begin{array}{l}\text { HIF- } 1 \alpha \text { expression } \\
\text { in primary tumors }\end{array}$} & \multirow[b]{2}{*}{$\chi^{2}$-value } & \multirow[b]{2}{*}{ P-value } & \multicolumn{2}{|c|}{$\begin{array}{l}\text { VEGF expression } \\
\text { in primary tumors }\end{array}$} & \multirow[b]{2}{*}{$\chi^{2}$-value } & \multirow[b]{2}{*}{ P-value } \\
\hline & Negative & Positive & & & Negative & Positive & & \\
\hline Patient, $\mathrm{n}$ & 14 & 32 & & & 12 & 34 & & \\
\hline Sex & & & 0.00 & 0.96 & & & 0.28 & 0.60 \\
\hline Male $(n=20)$ & 6 & 14 & & & 6 & 14 & & \\
\hline Female $(\mathrm{n}=26)$ & 8 & 18 & & & 6 & 20 & & \\
\hline Age, years & & & 0.08 & 0.93 & & & 0.02 & 0.90 \\
\hline$<60(\mathrm{n}=30)$ & 9 & 21 & & & 8 & 22 & & \\
\hline$\geq 60(n=16)$ & 5 & 11 & & & 4 & 12 & & \\
\hline Sites & & & 0.07 & 0.79 & & & 2.81 & 0.09 \\
\hline Colon $(n=35)$ & 11 & 24 & & & 7 & 28 & & \\
\hline Rectum (n=11) & 3 & 8 & & & 5 & 6 & & \\
\hline Tumor differentiation & & & 0.04 & 0.98 & & & 0.25 & 0.88 \\
\hline Low $(n=14)$ & 4 & 10 & & & 3 & 11 & & \\
\hline Moderate $(n=22)$ & 7 & 15 & & & 6 & 16 & & \\
\hline $\operatorname{High}(\mathrm{n}=10)$ & 3 & 7 & & & 3 & 7 & & \\
\hline Depth of invasion & & & 2.19 & 0.14 & & & 2.31 & 0.13 \\
\hline pT3 $(n=22)$ & 9 & 13 & & & 8 & 14 & & \\
\hline pT4 $(\mathrm{n}=24)$ & 5 & 19 & & & 4 & 20 & & \\
\hline Primary tumor size, $\mathrm{cm}$ & & & 0.15 & 0.70 & & & 1.05 & 0.31 \\
\hline$\leq 3(n=25)$ & 7 & 18 & & & 5 & 20 & & \\
\hline$>3(\mathrm{n}=21)$ & 7 & 14 & & & 7 & 14 & & \\
\hline
\end{tabular}

HIF-1 $\alpha$, hypoxia-inducible factor 1- $\alpha$; VEGF, vascular endothelial growth factor; pT, pathological stage of primary tumor.

$\mathrm{P}<0.05$ was considered to indicate a statistically significant difference and all statistical tests were two-sided.

\section{Results}

Association between HIF-1 $\alpha, V E G F$ and CD34 expression in primary and metastatic sites of CRC and clinicopathological characteristics. Positive HIF-1 $\alpha$ staining was predominantly located in the nucleus or cytoplasm with brown or brown yellow granules (Fig. 1), while positive VEGF staining was indicated by the presence of brownish-yellow granules in the cytoplasm or cell membrane (Fig. 2) and CD34 staining was observed in the vascular endothelium as brown sediments (Fig. 3). HIF-1 $\alpha$ was detectable (++ to +++$)$ in $70.0 \%$ of the primary tumors, $60.9 \%$ of the metastatic lymph nodes and $65.2 \%$ of the liver metastases. VEGF was detectable $(++$ to +++$)$ in $73.9 \%$ of the primary tumors, $58.7 \%$ of the metastatic lymph nodes and $67.4 \%$ of the liver metastases. The mean microvessel density was 16.2 (standard deviation=9.3), with a range of 4-37. For the high group of MVD, it accounted for $78.3 \%$ of the primary samples, $32.6 \%$ of the metastatic lymph nodes and $41.3 \%$ of the liver metastases. Although HIF-1 $\alpha$ and VEGF expression levels were frequently positive in primary tumors compared with corresponding metastases, no significant difference was observed. However, MVD scores demonstrated a significant difference between primary CRC and matched metastases (all $\mathrm{P}<0.05$ ). Univariate analysis demonstrated that no significant associations were observed between HIF-1 $\alpha$ and VEGF expression, and clinicopathological characteristics in primary lesions and metastatic sites (all P>0.05; Tables I-III).

Association in individual tumor marker expression between primary tumors and corresponding metastases. The association between HIF- $1 \alpha$ and VEGF status in primary tumors and paired metastatic lesions, and histological sections demonstrated consistency (Table IV). A total of 38 patients $(83 \%)$ with HIF-1 $\alpha$ and 35 patients (76\%) with VEGF exhibited concordance in expression between primary tumors and matched lymph node metastases. The correlation coefficient of HIF-1 $\alpha$ and VEGF were $(\mathrm{K}=0.62 ; \mathrm{P}<0.001)$ and $(\mathrm{K}=0.48$; $\mathrm{P}=0.001)$, respectively. Conversely, a total of 34 patients $(74 \%)$ with HIF-1 $\alpha$ and 39 patients $(85 \%)$ with VEGF exhibited concordance with regards to expression levels in primary tumors and liver metastases. The correlation coefficient of HIF- $1 \alpha$ and VEGF were $(\mathrm{K}=0.41 ; \mathrm{P}=0.005)$ and $(\mathrm{K}=0.64$; $\mathrm{P}<0.001)$, respectively.

Minor differences between primary tumors and metastatic lesions were still presented. Regarding HIF-1 $\alpha$ expression, eight cases demonstrated a discordance in expression between primary tumors and lymph node metastases ( $\mathrm{P}=0.29$; Table IV), 
Table II. Association between HIF-1 $\alpha$ and VEGF expression in metastatic lymph nodes and the clinicopathological characteristics of patients with colorectal carcinomas $(n=46)$.

\begin{tabular}{|c|c|c|c|c|c|c|c|c|}
\hline \multirow[b]{2}{*}{ Characteristic } & \multicolumn{2}{|c|}{$\begin{array}{l}\text { HIF-1 } \alpha \text { expression } \\
\text { in metastatic } \\
\text { lymph nodes }\end{array}$} & \multirow[b]{2}{*}{$\chi^{2}$-value } & \multirow[b]{2}{*}{ P-value } & \multicolumn{2}{|c|}{$\begin{array}{l}\text { VEGF expression } \\
\text { in metastatic } \\
\text { lymph nodes }\end{array}$} & \multirow[b]{2}{*}{$\chi^{2}$-value } & \multirow[b]{2}{*}{ P-value } \\
\hline & Negative & Positive & & & Negative & Positive & & \\
\hline Patient, $\mathrm{n}$ & 18 & 28 & & & 19 & 27 & & \\
\hline Sex & & & 2.97 & 0.09 & & & 1.87 & 0.17 \\
\hline Male $(n=20)$ & 5 & 15 & & & 6 & 14 & & \\
\hline Female $(n=26)$ & 13 & 13 & & & 13 & 13 & & \\
\hline Age, years & & & 1.22 & 0.27 & & & 1.02 & 0.31 \\
\hline$<60(\mathrm{n}=30)$ & 10 & 20 & & & 14 & 16 & & \\
\hline$\geq 60(n=16)$ & 8 & 8 & & & 5 & 11 & & \\
\hline Sites & & & 1.44 & 0.23 & & & 0.15 & 0.70 \\
\hline Colon $(n=35)$ & 12 & 23 & & & 15 & 20 & & \\
\hline Rectum $(n=11)$ & 6 & 5 & & & 4 & 7 & & \\
\hline Tumor differentiation & & & 4.74 & 0.09 & & & 5.68 & 0.06 \\
\hline Low $(n=14)$ & 6 & 8 & & & 3 & 11 & & \\
\hline Moderate $(n=22)$ & 11 & 11 & & & 13 & 9 & & \\
\hline $\operatorname{High}(\mathrm{n}=10)$ & 1 & 9 & & & 3 & 7 & & \\
\hline Depth of invasion & & & 0.71 & 0.40 & & & 0.00 & 0.96 \\
\hline pT3 $(n=22)$ & 10 & 12 & & & 9 & 13 & & \\
\hline pT4 $(n=24)$ & 8 & 16 & & & 10 & 14 & & \\
\hline Primary tumor size, $\mathrm{cm}$ & & & 0.23 & 0.64 & & & 2.58 & 0.11 \\
\hline$\leq 3(n=25)$ & 9 & 16 & & & 13 & 12 & & \\
\hline$>3(n=21)$ & 9 & 12 & & & 6 & 15 & & \\
\hline
\end{tabular}

HIF-1 $\alpha$, hypoxia-inducible factor 1- $\alpha$; VEGF, vascular endothelial growth factor; pT, pathological stage of primary tumor.

while 12 cases indicated discordance between primary tumors and liver metastases ( $\mathrm{P}=0.29$; Table IV). Among these, HIF-1 $\alpha$ immunostaining were negative expression in the primary tumor and positive expression in the metastatic lesions in seven cases, while opposing results were exhibited in the remaining 13 cases. Regarding VEGF expression, 11 cases demonstrated discordance in pairs of primary tumors and matched lymph node metastases ( $\mathrm{P}=0.45$; Table IV), while seven cases indicated discordant between primary tumors and matched liver metastases ( $\mathrm{P}=0.29$; Table IV). Among these, four cases exhibited positive expression in metastasis but negative expression in primary tumors, while opposing results were exhibited in the remaining 14 cases.

\section{Discussion}

Advanced colorectal cancer continues to present a major health problem worldwide. Similar to other types of malignant tumor, $\mathrm{CRC}$ is a systemic disease. Eliminating metastatic lesions allows for successful comprehensive surgical treatment. Hypoxia and angiogenesis are a common phenomenon in solid tumors, which play key roles in cancer progression (19). HIF-1 $\alpha$ and VEGF are the most potent angiogenic proteins, which promote malignant transformation, angiogenesis and metastatic dissemination (20).
Currently, patients with $\mathrm{mCRC}$ resistant to chemotherapy benefit from anti-angiogenesis-targeted therapies, such as bevacizumab, which has been widely applied in clinical practice (21). Unlike epidermal growth factor receptor (EGFR), angiogenesis inhibitors do not have specific target populations and present no clear indications for clinical application in CRC. The benefit of angiogenesis inhibitors is that the unselected patient population are modest (22). However, whether primary CRC and their associated metastases have similar levels of angiogenesis has not yet been determined. This gap in the literature is primarily attributable to the incorrect assumption that primary CRC and metastatic lesions are pathologically consistent (12). Thus, the comparative analysis of HIF-1 $\alpha$, VEGF and MVD differences between primary and metastatic tumors may improve understanding of the changes of metastases, promote research and application of novel targeted drugs and provide information to predict whether anti-angiogenesis targeted drugs may benefit patients with $\mathrm{mCRC}$.

According to published data, HIF-1 $\alpha$ and VEGF upregulation in $\mathrm{CRC}$ at the protein level ranges from 55-65 and 44-64\%, respectively, while less expression is observed in normal tissues $(23,24)$, and relatively little is known about the role of hypoxia and angiogenesis in metastases. In the present study, hypoxia and angiogenesis in lymph node and 
Table III. Association between HIF-1 $\alpha$ VEGF in liver metastases and the clinicopathological characteristics of patients with colorectal carcinomas $(n=46)$.

\begin{tabular}{|c|c|c|c|c|c|c|c|c|}
\hline \multirow[b]{2}{*}{ Characteristic } & \multicolumn{2}{|c|}{$\begin{array}{l}\text { HIF- } 1 \alpha \text { expression } \\
\text { in liver metastases }\end{array}$} & \multirow[b]{2}{*}{$\chi^{2}$-value } & \multirow[b]{2}{*}{ P-value } & \multicolumn{2}{|c|}{$\begin{array}{l}\text { VEGF expression } \\
\text { in liver metastases }\end{array}$} & \multirow[b]{2}{*}{$\chi^{2}$-value } & \multirow[b]{2}{*}{ P-value } \\
\hline & Negative & Positive & & & Negative & Positive & & \\
\hline Patient, $\mathrm{n}$ & 16 & 30 & & & 15 & 31 & & \\
\hline Sex & & & 0.36 & 0.55 & & & 2.56 & 0.11 \\
\hline Male $(n=20)$ & 6 & 14 & & & 4 & 16 & & \\
\hline Female $(n=26)$ & 10 & 16 & & & 11 & 15 & & \\
\hline Age, years & & & 1.04 & 0.31 & & & 0.02 & 0.89 \\
\hline$<60(\mathrm{n}=30)$ & 12 & 18 & & & 10 & 20 & & \\
\hline$\geq 60(n=16)$ & 4 & 12 & & & 5 & 11 & & \\
\hline Sites & & & 1.76 & 0.19 & & & 0.19 & 0.67 \\
\hline Colon $(n=35)$ & 14 & 21 & & & 12 & 23 & & \\
\hline Rectum $(n=11)$ & 2 & 9 & & & 3 & 8 & & \\
\hline Tumor differentiation & & & 2.83 & 0.24 & & & 0.10 & 0.95 \\
\hline Low $(n=14)$ & 6 & 8 & & & 5 & 9 & & \\
\hline Moderate $(n=22)$ & 5 & 17 & & & 7 & 15 & & \\
\hline $\operatorname{High}(\mathrm{n}=10)$ & 5 & 5 & & & 3 & 7 & & \\
\hline Depth of invasion & & & 0.70 & 0.40 & & & 0.01 & 0.91 \\
\hline pT3 $(n=22)$ & 9 & 13 & & & 7 & 15 & & \\
\hline pT4 $(n=24)$ & 7 & 17 & & & 8 & 16 & & \\
\hline Primary tumor size, $\mathrm{cm}$ & & & 0.66 & 0.42 & & & 3.23 & 0.07 \\
\hline$\leq 3(n=25)$ & 10 & 15 & & & 11 & 14 & & \\
\hline$>3(n=21)$ & 6 & 15 & & & 4 & 17 & & \\
\hline
\end{tabular}

HIF-1 $\alpha$, hypoxia-inducible factor $1-\alpha$; VEGF, vascular endothelial growth factor.
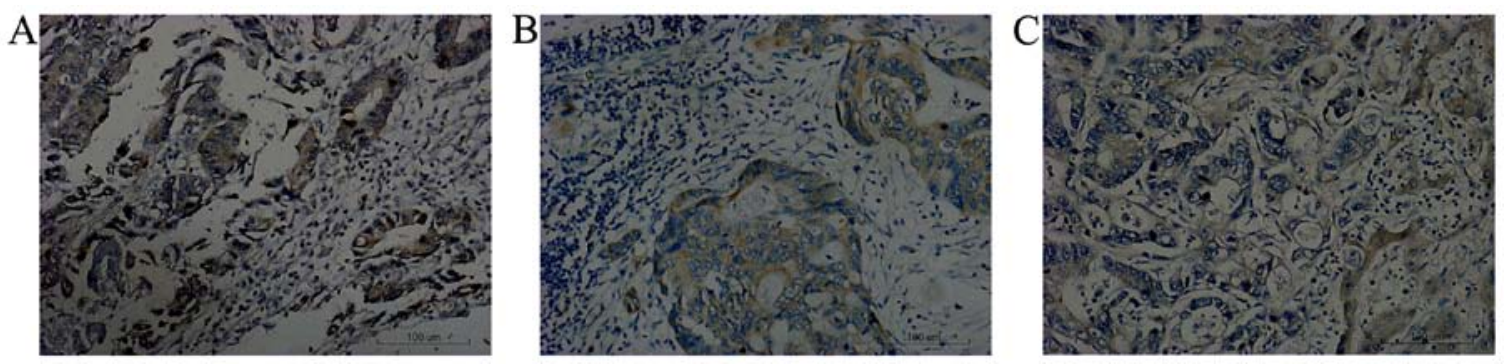

Figure 1. Immunohistochemical staining of hypoxia-inducible factor 1 alpha. (A) Primary tumor, (B) lymph node metastasis and (C) liver metastasis demonstrated concordance from the same patient with T3N2M1 (all positive, A and C showing ++ and B showing +++). Scale bar, $100 \mu \mathrm{m}$. Magnification, x200. TNM, tumor-node-metastasis.

liver metastases tissues of 46 patients with mCRC were investigated and compared with the primary tumor. HIF-1 $\alpha$, VEGF and CD34 were positively expressed at both sites, indicating that they were closely associated with the occurrence and development of mCRC (25). Further research and analysis demonstrated no significant difference in the expression levels of HIF-1 $\alpha$ and VEGF across different ages, sex, tumor sizes and degrees of histological differentiation. The current results are consistent with previous findings of the major of studies published to date $(26,27)$. A previous study reported that HIF-1 $\alpha$ and VEGF expression are frequently associated with depth of invasion (28). Although the positive rate of HIF-1 $\alpha$ and VEGF in patients with pT4 was slightly higher than that of patients with pT3 in both primary tumors and metastases in the present study, no significant difference was observed. These results are also inconsistent with findings reported in the literature and may be associated with all patients with distant metastasis in stage IV of the present study.

In order to fully utilize individualized treatment in molecular targeted therapies, an immunohistochemical evaluation of target molecule expression at the primary tumor site, as well as at metastatic sites is required to provide value for 

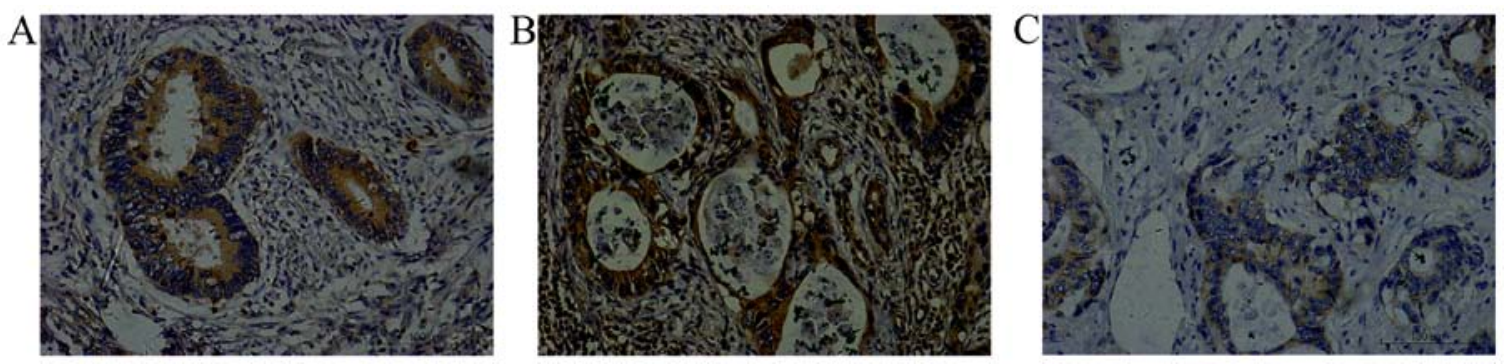

Figure 2. Immunohistochemical staining of vascular endothelial growth factor. (A) Primary tumor, (B) lymph node metastasis and (C) liver metastasis demonstrated concordance from the same patient with T3N1M1 (all positive, B and C showing ++ and A showing +++ ). Scale bar, 100 $\mu$ m. Magnification, x200. TNM, tumor-node-metastasis.
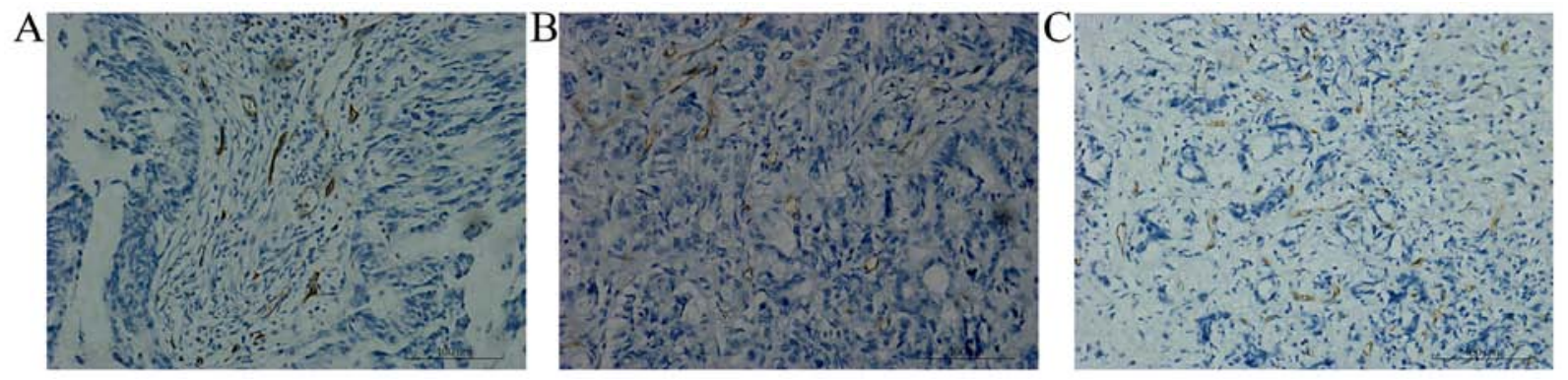

Figure 3. Immunohistochemical staining of CD34. (A) Primary tumor, (B) lymph node metastasis and (C) liver metastasis demonstrated concordance from the samepatient with T3N1M1 (all positive, B and C showing ++ and A showing +++). Scale bar, $100 \mu \mathrm{m}$. Magnification, x100. TNM, tumor-node-metastasis.

therapeutic decisions and decrease high costs (29). However, regarding the expression of angiogenesis markers in metastatic sites of CRC, only a few cases have been reported in the literature, and the research results are inconsistent. For example, Shim et al (30) demonstrated that HIF-1 $\alpha$ expression is higher in metastatic lymph nodes compared with primary lesions in breast cancer. However, Fraga et al (31) reported that there is no difference in HIF-1 $\alpha$ protein expression between primary lesions and metastatic sites in the upper aerodigestive tract of patients with cancer. Due to the fact that metastases are not easily accessible from the same patients in clinical work, several aspects of the molecular mechanism of CRC metastasis are yet to be elucidated. The results of the present study demonstrated that HIF-1 $\alpha$ and VEGF expression levels in corresponding metastases were lower than in primary tumors; however, only the difference in MVD value was statistically significant. This indicates that compared with metastases, there may be less oxygen in primary tumors, and hypoxia may provide the stimulus that upregulates HIF-1 $\alpha$ and VEGF transcription and malignancy (27). In most types of human malignant tumor, the vasculature is a direct result of angiogenesis. MVD is one marker of tumor angiogenesis (32). The present study used CD34 to detect MVD in primary colorectal tumors and matched metastases, and it was revealed that the metastases were poorly vascularised compared with the primary tumors. This was not consistent with the trends seen in HIF-1 $\alpha$ and VEGF expression. In CRC, the primary tumor suppresses the vascularization of distant metastases, and the vascular density of the primary tumor is higher than its metastases (33). Furthermore, a variety of internal environmental factors may affect angiogenesis in metastatic lesions. For example, in lymph node metastases, which may have a good blood supply, the growth of metastatic lesions in the lymph nodes is not dependent on angiogenesis (34). Additionally, anti-tumor immunity in lymph nodes may be associated with the inhibition of neovascularization, thereby explaining the low MVD $(35,36)$. In clinical studies, although patients with CRC received neoadjuvant chemotherapy and bevacizumab, lymph node metastases were still observed at the time of surgery and pathological evaluation, suggesting a lack of response of lymph node metastasis to anti-angiogenic therapy (37). The replacement pattern is one of three growth patterns of liver metastases of CRC, in which tumor cells simply replace hepatocytes, and where the liver architecture and sinusoidal blood vessels provide an angiogenic prosperous environment for metastatic tumor growth $(38,39)$. Additionally, blood vessels surrounding liver metastasis are heterogeneous, and the relatively high levels of oxygen in the highly vascular liver that cause MVD are less of an angiogenic driving force $(40,41)$. MVD is different in primary CRC and metastatic lesions, suggesting that close attention should be paid to the changes of molecular indicators in the course of disease progression, which may inform the treatment strategy of patients. Thus, the blood vessels of metastases may respond in a different way to anti-angiogenic therapy and partially explain the unsatisfactory therapeutic effect of anti-angiogenic and/or anti-vascular treatments, such as bevacizumab, supporting the low MVD measured in previous studies of metastases $(41,42)$. Nevertheless, HIF-1 $\alpha$ and VEGF were highly expressed in corresponding metastases in the present study, supporting the notion of targeted therapies, such as anti-HIF-1 $\alpha$ /anti-VEGF monoclonal antibodies, which may be involved in the metastasis of CRC and may serve as a novel target to treat mCRC (43). 
Table IV. HIF-1 $\alpha$ and VEGF expression between primary tumors and corresponding metastases.

A, HIF-1 $\alpha$ expression between primary tumors and corresponding lymph node metastases $(n=46)$

\begin{tabular}{|c|c|c|c|c|c|}
\hline \multirow[b]{2}{*}{ Primary tumor } & \multicolumn{2}{|c|}{$\begin{array}{l}\text { Regional lymph } \\
\text { node metastasis }\end{array}$} & \multirow[b]{2}{*}{ Concordance, n/total n (\%) } & \multirow[b]{2}{*}{ Discordance, $\mathrm{n} /$ total n (\%) } & \multirow[b]{2}{*}{ McNemar P-value } \\
\hline & Negative, $\mathrm{n}$ & Positive, $\mathrm{n}$ & & & \\
\hline Negative, $\mathrm{n}$ & 12 & 2 & $38 / 46(83)$ & $8 / 46(17)$ & 0.29 \\
\hline Positive, $\mathrm{n}$ & 6 & 26 & & & \\
\hline
\end{tabular}

B, HIF-1 $\alpha$ expression between primary tumors and synchronous liver metastasis $(n=46)$

Synchronous liver metastasis

Primary tumor Negative, $\mathrm{n} \quad$ Positive, $\mathrm{n} \quad$ Concordance, $\mathrm{n} /$ total n (\%) $\quad$ Discordance, n/total n (\%) $\quad$ McNemar P-value

\begin{tabular}{|c|c|c|c|c|c|}
\hline Negative, $\mathrm{n}$ & 9 & 7 & $34 / 46(74)$ & $12 / 46(26)$ & 0.29 \\
\hline Positive, $\mathrm{n}$ & 7 & 25 & & & \\
\hline
\end{tabular}

C, VEGF expression between primary tumors and corresponding lymph node metastases $(\mathrm{n}=46)$

Regional lymph

node metastasis

Primary tumor Negative, $\mathrm{n} \quad$ Positive, $\mathrm{n} \quad$ Concordance, $\mathrm{n} /$ total $\mathrm{n}(\%) \quad$ Discordance, $\mathrm{n} /$ total n $(\%) \quad$ McNemar P-value

\begin{tabular}{lrrrr}
\hline Negative, $\mathrm{n}$ & 10 & 2 & $35 / 46(76)$ & $11 / 46(24)$ \\
Positive, $\mathrm{n}$ & 9 & 25 & & \\
\hline
\end{tabular}

D, VEGF expression between primary tumors and synchronous liver metastasis $(n=46)$

\begin{tabular}{|c|c|c|c|c|c|}
\hline \multirow[b]{2}{*}{ Primary tumor } & \multicolumn{2}{|c|}{$\begin{array}{c}\text { Synchronous liver } \\
\text { metastasis }\end{array}$} & \multirow[b]{2}{*}{ Concordance, n/total n (\%) } & \multirow[b]{2}{*}{ Discordance, n/total n (\%) } & \multirow[b]{2}{*}{ McNemar P-value } \\
\hline & Negative, $\mathrm{n}$ & Positive, $\mathrm{n}$ & & & \\
\hline Negative, $\mathrm{n}$ & 10 & 5 & $39 / 46(85)$ & $7 / 46(15)$ & 0.29 \\
\hline Positive, $\mathrm{n}$ & 2 & 29 & & & \\
\hline
\end{tabular}

HIF-1 $\alpha$, hypoxia-inducible factor 1- $\alpha$; VEGF, vascular endothelial growth factor; N, negative; P, positive.

Whether HIF-1 $\alpha$ and VEGF expression between primary and metastatic colorectal cancer is consistent has rarely been reported in the literature. Shimomura et al (19) reported that HIF-1 $\alpha$ expression levels in liver metastases is significantly associated with that in the corresponding primary tumor. Furthermore, Nakamoto et al (44) analysed VEGF tissue samples from pairs of primary tumors and corresponding metastatic liver tumors and reported that the primary and associated metastatic liver demonstrated concordant immunoreactivity for VEGF in CRC. Kobayashi et al (45) also reported that VEGF expression in hepatic metastatic tumors is positively associated with its expression level in primary tumors in CRC. The results of the present study demonstrated that in 46 pairs of primary tumors and matched metastases, 38 patients $(83 \%)$ for HIF-1 $\alpha$ and 35 cases $(76 \%)$ for VEGF demonstrated concordance in lymph node metastases, and 34 patients (74\%) for HIF-1 $\alpha$ and 39 cases $(85 \%)$ for VEGF indicated consistency in liver metastases. This suggests that patients with high angiogenesis activity in primary cancer also exhibit a high degree of angiogenesis in the corresponding metastatic sites. Concordance may indicate that primary tumors and corresponding metastases have the same genomic status and that cancer cells remain notably stable in metastatic tumors (13). Thus, the expression profiles of HIF-1 $\alpha$ and VEGF during the metastatic process were mainly unchanged. The data suggest that detection of HIF-1 $\alpha$ and VEGF expression in either a primary tumor or metastases may be reliable indicator used to inform treatment decisions with HIF-1 $\alpha$ and/or VEGF inhibitors (19). Targeted therapy for HIF- $1 \alpha$ and VEGF in metastases may achieve good therapeutic effects; however, further investigations with more cases are needed to confirm these findings. 
Minor differences were observed between primary tumors and metastatic lesions in the present study. The molecular mechanism by which metastasis occurs is hypothesized to exist in a small population of cells in the primary tumor, and these changes result in the emergence of metastases (12). This hypothesis would predict a degree of difference in protein expression between primary tumors and metastases. Additionally, the expression of biomarkers is prone to be influenced by several clinicopathological and local microenvironments of the liver and lymph node (46). Thus, a certain degree of difference in protein expression may exist between primary tumors and corresponding metastases. In the present study, when matched tissue sets were compared on an individual basis, eight cases demonstrated discordant HIF-1 $\alpha$ expression, and 11 cases exhibited discordant VEGF expression, in 46 pairs of primary tumors and paired metastatic lymph nodes. A discordant rate of 26 and $15 \%$ were observed for HIF- $1 \alpha$ and VEGF expression between primary tumors and liver metastases, respectively, with no statistical difference. Thus, major concordance and minor differences are observed between primary CRCs and corresponding metastases, suggesting that the inhibitors of HIF-1 $\alpha$ and VEGF are effective in mCRC.

In conclusion, HIF-1 $\alpha$ and VEGF were overexpressed in both primary and matched metastatic tissues of CRC. HIF- $1 \alpha$ and VEGF expression status of the primary tumor were concordant with corresponding metastases, suggesting that the markers are stable in the process of metastasis and provide a reliable basis for predicting the angiogenic activity of metastases by analysing the primary tumor. Based on the present data, the results represent important implications for understanding the biology of metastasis in $\mathrm{mCRC}$, providing evidence for further use of inhibitors of HIF-1 $\alpha$ and VEGF. However, the local microenvironment of metastases may affect the angiogenesis of tumor cells. Differences in angiogenesis of different metastatic sites may have different therapeutic consequences when treatment with anti-angiogenic therapy is considered, thus further research is required.

\section{Acknowledgements}

Not applicable.

\section{Funding}

The present study was supported by the Science and Technology Development Plan of Jinan (grant nos. 201805091 and 201401253) and the Postdoctoral Science Foundation of China (grant no. 2017M612317).

\section{Availability of data and materials}

The datasets used and/or analyzed during the current study are available from the corresponding author on reasonable request.

\section{Authors' contributions}

YS conceived and designed the present study. LY, JL and DM performed the experiments. DL participated in immunohistochemistry and performed the statistical analysis. LY and
DL reviewed and edited the manuscript. All authors read and approved the final manuscript.

\section{Ethics approval and consent to participate}

The present study was approved by the Ethics and Scientific Committees of Shandong Cancer Hospital (Shandong, China) and performed in accordance with The Declaration of Helsinki. Written informed consent was obtained from all patients prior to the study start.

\section{Patient consent for publication}

Not applicable.

\section{Competing interests}

The authors declare that they have no competing interests.

\section{References}

1. Bray F, Ferlay J, Soerjomataram I, Siegel RL, Torre LA and Jemal A: Global cancer statistics 2018: GLOBOCAN estimates of incidence and mortality worldwide for 36 cancers in 185 countries. CA Cancer J Clin 68: 394-424, 2018.

2. Song X, Zhao Z, Barber B, Gregory C, Schutt D and Gao S: Characterizing medical care by disease phase in metastatic colorectal cancer. Am J Manag Care 17 (Suppl 5): SP20-SP25, 2011.

3. Devesa H, Pereira L, Gonçalves A, BritoT, Almeida T, Torres R and Midoes A: Axillary lymph node metastasis of colon cancer-case report and literature review. Case Rep Clin Med 12: 669-673, 2014.

4. Kirstein MM, Lange A, Prenzler A, Manns MP, Kubicka S and Vogel A: Targeted therapies in metastatic colorectal cancer: A systematic review and assessment of currently available data. Oncologist 19: 1156-1168, 2014.

5. Kim DH, Sung B, Kang YJ, Hwang SY, Kim MJ, Yoon JH, Im E and Kim ND: Sulforaphane inhibits hypoxia-induced HIF-1a and VEGF expression and migration of human colon cancer cells. Int J Oncol 47: 2226-2232, 2015.

6. Ajith TA: Current insights and future perspectives of hypoxia-inducible factor targeted therapy in cancer. J Basic Clin Physiol Pharmacol 30: 11-18, 2018.

7. Semenza GL: HIF-1 mediates metabolic responses to intratumoral hypoxia and oncogenic mutations. J Clin Invest 123: 3664-3671, 2013.

8. Nieves BJ, D'Amore PA and Bryan BA: The function of vascular endothelial growth factor. Biofactors 35: 332-337, 2009.

9. Iwasaki K, Yabushita H, Ueno T and Wakatsuki A: Role of hypoxia-inducible factor-1 $\alpha$, carbonic anhydrase-IX, glucose transporter-1 and vascular endothelial growth factor associated with lymph node metastasis and recurrence in patients with locally advanced cervical cancer. Oncol Lett 10: 1970-1978, 2015.

10. Brahimi-Horn MC, Chiche J and Pouyssegur J: Hypoxia and cancer. J Mol Med (Berl) 85: 1301-1307, 2007.

11. Cohen SA, Yu M, Baker K, Redman M, Wu C, Heinzerling TJ, Wirtz RM, Charalambous E, Pentheroudakis G, Kotoula V, et al: The $\mathrm{CpG}$ island methylator phenotype is concordant between primary colorectal carcinoma and matched distant metastases. Clin Epigenetics 9: 46, 2017.

12. Luo KJ, Hu Y, Wen J and Fu JH: CyclinD1, p53, E-cadherin, and VEGF discordant expression in paired regional metastatic lymph nodes of esophageal squamous cell carcinoma: A tissue array analysis. J Surg Oncol 104: 236-243, 2011.

13. Knosel T, Schluns K, Dietel M and Petersen I: Chromosomal alterations in lung metastases of colorectal carcinomas: Associations with tissue specific tumor dissemination. Clin Exp Metastasis 22: 533-538, 2005

14. Wu Y, Jin M, Xu H, Shimin Z, He S, Wang L and Zhang Y: Clinicopathologic significance of HIF-1 $\alpha$, CXCR4, and VEGF expression in colon cancer. Clin Dev Immunol 2010: pii: 537531, 2010. 
15. Qiu Y and Zhou H: Expression of HIF-1alpha and VEGF in human laryngeal carcinoma and its relationship with angiogenes. Lin Chung Er Bi Yan Hou Tou Jing Wai Ke Za Zhi 28: 389-393, 2014 (In Chinese).

16. Matsuo Y, Ding Q, Desaki R, Maemura K, Mataki Y, Shinchi H, Natsugoe S and Takao S: Hypoxia inducible factor-1 alpha plays a pivotal role in hepatic metastasis of pancreatic cancer: An immunohistochemical study. J Hepatobiliary Pancreat Sci 21: 105-112, 2014

17. Schlingemann RO, Rietveld FJ, de Waal RM, Bradley NJ, Skene AI, Davies AJ, Greaves MF, Denekamp J and Ruiter DJ: Leukocyte antigen CD34 is expressed by a subset of cultured endothelial cells and on endothelial abluminal microprocesses in the tumor stroma. Lab Invest 62: 690-696, 1990.

18. Hlatky L, Hahnfeldt P and Folkman J: Clinical application of antiangiogenic therapy: microvessel density, what it does and doesn't tell us. J Natl Cancer Inst 94: 883-893, 2002.

19. Shimomura M, Hinoi T, Kuroda S, Adachi T, Kawaguchi Y, Sasada T, Takakura Y, Egi H, Okajima M, Tashiro H, et al: Overexpression of hypoxia inducible factor-1 alpha is an independent risk factor for recurrence after curative resection of colorectal liver metastases. Ann Surg Oncol 20 (Suppl 3): S527-S536, 2013.

20. Hurwitz H, Fehrenbacher L, Novotny W, Cartwright T, Hainsworth J, Heim W, Berlin J, Baron A, Griffing S, Holmgren E, et al: Bevacizumab plus irinotecan, fluorouracil, and leucovorin for metastatic colorectal cancer. N Engl J Med 350: 2335-2342, 2004

21. Jensen NF, Smith DH, Nygard SB, Romer MU, Nielsen KV and Brunner N: Predictive biomarkers with potential of converting conventional chemotherapy to targeted therapy in patients with metastatic colorectal cancer. Scand J Gastroenterol 47: 340-355, 2012

22. Ulivi P, Marisi G and Passardi A: Relationship between hypoxia and response to antiangiogenic therapy in metastatic colorectal cancer. Oncotarget 7: 46678-46691, 2016.

23. Cao D, Hou M, Guan YS, Jiang M, Yang Y and Gou HF: Expression of HIF-1alpha and VEGF in colorectal cancer: Association with clinical outcomes and prognostic implications. BMC cancer 9: 432, 2009.

24. Simiantonaki N, Taxeidis M, Jayasinghe C, Kurzik-Dumke U and Kirkpatrick CJ: Hypoxia-inducible factor 1 alpha expression increases during colorectal carcinogenesis and tumor progression. BMC Cancer 8: 320, 2008.

25. Berk V, Deniz K, Bozkurt O, Ozaslan E, Karaca H, Inanc M, Duran AO and Ozkan M: Predictive significance of VEGF and HIF-1 $\alpha$ expression in patients with metastatic colorectal cancer receiving chemotherapy combinations with bevacizumab. Asian Pac J Cancer Prev 16: 6149-6154, 2015.

26. Kurokawa T, Miyamoto M, Kato K, Cho Y, Kawarada Y, Hida Y, Shinohara T, Itoh T, Okushiba S, Kondo S and Katoh H: Overexpression of hypoxia-inducible-factor 1alpha (HIF-1alpha) in oesophageal squamous cell carcinoma correlates with lymph node metastasis and pathologic stage. Br J Cancer 89: 1042-1047, 2003.

27. Maxwell PH, Dachs GU, Gleadle JM, Nicholls LG, Harris AL, Stratford IJ, Hankinson O, Pugh CW and Ratcliffe PJ: Hypoxia-inducible factor-1 modulates gene expression in solid tumors and influences both angiogenesis and tumor growth. Proc Natl Acad Sci USA 94: 8104-8109, 1997.

28. Ioannou M,ParaskevaE, Baxevanidou K, Simos G,Papamichali R, Papacharalambous C, Samara M and Koukoulis G: HIF-1 $\alpha$ in colorectal carcinoma: Review of the literature. J BUON 20: 680-689, 2015

29. Bar J, Herbst RS and Onn A: Targeted drug delivery strategies to treat lung metastasis. Expert Opin Drug Deliv 6: 1003-1016, 2009.

30. Shim H, Lau SK, Devi S, Yoon Y, Cho HT and Liang Z: Lower expression of CXCR4 in lymph node metastases than in primary breast cancers: Potential regulation by ligand-dependent degradation and HIF-1alpha. Biochem Biophys Res Commun 346: 252-258, 2006

31. Fraga CA, de Oliveira MV, de Oliveira ES, Barros LO, Santos FB, Gomez RS, De-Paula AM and Guimarães AL: A high HIF-1a expression genotype is associated with poor prognosis of upper aerodigestive tract carcinoma patients. Oral Oncol 48: 130-135, 2012.

32. Jilaveanu LB, Puligandla M, Weiss SA, Wang XV, Zito C, Flaherty KT, Boeke M, Neumeister V, Camp RL, Adeniran A, Pins M, et al: Tumor microvessel density as a prognostic marker in high-risk renal cell carcinoma patients treated on ECOG-ACRIN E2805. Clin Cancer Res 24: 217-223, 2018.
33. Peeters CF, Westphal JR, de Waal RM, Ruiter DJ, Wobbes T and Ruers TJ: Vascular density in colorectal liver metastases increases after removal of the primary tumor in human cancer patients. Int J Cancer 112: 554-559, 2004.

34. Guo M, Mu Y, Yu D, Li J, Chen F, Wei B, Bi S, Yu J and Liang F: Comparison of the expression of TGF- $\beta 1$, E-cadherin, $\mathrm{N}$-cadherin, TP53, RB1CC1 and HIF-1 $\alpha$ in oral squamous cell carcinoma and lymph node metastases of humans and mice. Oncol Lett 15: 1639-1645, 2018.

35. Jeong HS, Jones D, Liao S, Wattson DA, Cui CH, Duda DG, Willett CG, Jain RK and Padera TP: Investigation of the lack of angiogenesis in the formation of lymph node metastases. J Natl Cancer Inst 107: pii: djv155, 2015.

36. Roberts N, Kloos B, Cassella M, Podgrabinska S, Persaud K, Wu Y, Pytowski B and Skobe M: Inhibition of VEGFR-3 activation with the antagonistic antibody more potently suppresses lymph node and distant metastases than inactivation of VEGFR-2. Cancer Res 66: 2650-2657, 2006.

37. Willett CG, Duda DG, Ancukiewicz M, Shah M, Czito BG, Bentley R, Poleski M, Fujita H, Lauwers GY, Carroll M, et al: A safety and survival analysis of neoadjuvant bevacizumab with standard chemoradiation in a phase I/II study compared with standard chemoradiation in locally advanced rectal cancer. Oncologist 15: 845-851, 2010

38. Stessels F, Van den Eynden G, Van der Auwera I, Salgado R, V n den Heuvel E, Harris AL, Jackson DG, Colpaert CG, van Marck EA, Dirix LY and Vermeulen PB: Breast adenocarcinoma liver metastases, in contrast to colorectal cancer liver metastases, display a non-angiogenic growth pattern that preserves the stroma and lacks hypoxia. Br J Cancer 90: 1429-1436, 2004.

39. van der Wal GE, Gouw AS, Kamps JA, Moorlag HE, Bulthuis ML, Molema G and de Jong KP: Angiogenesis in synchronous and metachronous colorectal liver metastases: The liver as a permissive soil. Ann Surg 255: 86-94, 2012.

40. Rajaganeshan R, Prasad R, Guillou PJ, Scott N, Poston G and Jayne DG: Expression patterns of hypoxic markers at the invasive margin of colorectal cancers and liver metastases. Eur J Surg Oncol 35: 1286-1294, 2009.

41. Raluca BA, Cimpean AM, Cioca A, Cretu O, Mederle O, Ciolofan A, Gaje P and Raica M: Endothelial cell proliferation and vascular endothelial growth factor expression in primary colorectal cancer and corresponding liver metastases. Asian Pac J Cancer Prev 6: 4549-4553, 2015.

42. Sandhu J, Lavingia V and Fakih M: Systemic treatment for metastatic colorectal cancer in the era of precision medicine. J Surg Oncol 119: 564-582, 2019.

43. Kim YW, Ko YT, Kim NK, Chung HC, Min BS, Lee KY, Park JP and Kim H: A comparative study of protein expression in primary colorectal cancer and synchronous hepatic metastases: The significance of matrix metalloproteinase-1 expression as a predictor of liver metastasis. Scand J Gastroenterol 45: 217-225, 2010.

44. Nakamoto RH, Uetake H, Iida S, Kolev YV, Soumaoro LT, Takagi Y, Yasuno M and Sugihara K: Correlations between cyclooxygenase-2 expression and angiogenic factors in primary tumors and liver metastases in colorectal cancer. Jpn J Clin Oncol 37: 679-685, 2007.

45. Kobayashi H, Sugihara K, Uetake H, Higuchi T, Yasuno M, Enomoto M, Kuramochi H, Lenz HJ, Danenberg KD and Danenberg PV: Messenger RNA expression of vascular endothelial growth factor and its receptors in primary colorectal cancer and corresponding liver metastasis. Ann Surg Oncol 15: $1232-1238,2008$

46. Klein CA: Parallel progression of primary tumors and metastases. Nat Rev Cancer 9: 302-312, 2009.

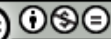

This work is licensed under a Creative Commons Attribution-NonCommercial-NoDerivatives 4.0 International (CC BY-NC-ND 4.0) License. 